\title{
COMPROMETIMENTO ORGANIZACIONAL: UM ESTUDO DE CASO NO SUPERMERCADO "BETA"
}

\author{
ORGANIZATIONAL COMMITMENT: \\ A CASE STUDY IN "BETA" SUPERMARKET
}

\author{
Michele Müller ${ }^{1}$; Eliane de Fátima Rauski ${ }^{2}$; Ivanilde Scussiatto Eyng ${ }^{3}$; Joelma Moreira ${ }^{4}$ \\ ${ }^{1}$ Universidade Estadual de Ponta Grossa - Ponta Grossa - Brasil \\ michelemulleradm@hotmail.com \\ ${ }^{2}$ Universidade Estadual de Ponta Grossa - Ponta Grossa - Brasil - erauski@uepg.br \\ ${ }^{3}$ Universidade Estadual de Ponta Grossa - UEPG - Ponta Grossa - Brasil \\ adm.ivanilde@uol.com.br \\ ${ }^{4}$ Universidade Estadual de Ponta Grossa - Ponta Grossa - Brasil - joelma_rh@hotmail.com
}

Recebido para publicação em: 01/06/05 Aceito para publicação em: 05/10/05

\begin{abstract}
Resumo
O presente artigo descreve um estudo de caso, tendo como eixo central de investigação, o comprometimento organizacional, além de identificar o grau, as dimensões e os padrões do comprometimento que os colaboradores apresentam e identificar a influência das características pessoais (idade, sexo, estado civil, nível de escolaridade, número de dependentes e nível de renda), das relações com a equipe e da permanência na organização no comprometimento com a empresa. $A$ análise dos dados, primeiramente, permitiu concluir que, cerca de $70 \%$ dos colaboradores apresentam um alto grau de comprometimento com a organização, que resulta em funcionários dispostos a exercer esforço em benefício da empresa pesquisada.
\end{abstract}

Palavras chave: Comprometimento organizacional; dimensões; padrões de comprometimento.

\section{Introdução}

As organizações estão inseridas em um ambiente turbulento, onde as aceleradas mudanças econômicas, políticas e sociais têm sido apontadas como fatores de grande impacto sobre o ambiente de trabalho e sobre as relações entre indivíduos e organizações. Segundo Vergara (2000) as disputas organizacionais por mercados têm tornado o mundo cada vez mais competitivo.

Desta forma, para se obter vantagens competitivas e atingir suas metas, as organizações necessitam de pessoas comprometidas que se identifiquem com a organização, para que isso aconteça se faz necessário que a empresa possibilite condições para que seus colaboradores alcancem seus objetivos pessoais.

Este estudo tem por objetivo identificar o grau de comprometimento organizacional, as dimensões e padrões de comprometimento existentes entre os colaboradores do Supermercado "Beta". O interesse no tema comprometimento está baseado na evidência de que dele derivam atitudes e comportamentos que aumentam o desempenho do colaborador. Este trabalho também 
abre uma lacuna para pesquisas futuras em outras empresas.

\section{Comprometimento organizacional}

As pesquisas de comprometimento organizacional possuem uma premissa em comum de que o comprometimento sozinho não garante o sucesso da empresa, mas que um elevado grau de comprometimento com a organização contribui para que as empresas alcancem seus objetivos. Segundo Teixeira, o estudo do comprometimento possibilita "a melhor compreensão da natureza dos processos psicológicos pelos quais as pessoas escolhem identificar-se com os objetivos em seu ambiente [...]" (1994, p.268).

Comprometer-se significa: sentir-se vinculado a algo e ter desejo de permanecer naquele curso de ação. (BASTOS, 1997). De acordo com Senge (1998, p.246), o comprometimento pressupõe "um sentimento total de responsabilidade na transformação das metas e objetivos em realidade".

Conforme Bastos (1997) o indivíduo articula seus vínculos de comprometimento com diferentes focos. No trabalho de Morrow (apud Bastos, 1997), trabalho este que se tornou um marco importante na área, a autora trabalha com cinco focos, a saber: valores, organização, carreira, trabalho e sindicato. Sendo que esta pesquisa estudará o comprometimento apenas com foco na organização, apresentando diferentes abordagens quanto às dimensões do comprometimento organizacional.

Bastos, Brandão e Pinho (1996) comentam que uma das características individuais mais estudadas, a partir dos anos 70, tem sido o comprometimento organizacional enfatizando especialmente a sua influência no alcance dos objetivos organizacionais. Colaboradores comprometidos com os objetivos da organização têm interesse em fazer o que for preciso para atingi-los.

Mais que uma simples lealdade à organização, o comprometimento é um processo através do qual os colaboradores expressam sua preocupação com o bem-estar e o sucesso da organização em que trabalham. (Northcaft e Neale apud Moraes, 1995, p.178).

Mowday et al. (1982, p.27) conceituam comprometimento organizacional como uma força relacionada com a identificação e o envolvimento das pessoas com uma organização específica. Afirmam que o comprometimento organizacional pode ser caracterizado por no mínimo três fatores: a) uma forte crença e a aceitação dos objetivos e valores da organização; b) estar disposto em exercer um esforço considerável em benefício da organização; c) um forte desejo de se manter membro da organização.

O comprometimento para Davenport (2001, p.38-40) se refere ao elo de ligação entre a pessoas e a organização, de base emocional ou intelectual, e é dividido por ele em três categorias:

a) Atitudinal: pessoas que se identificam e se envolvem com a organização e gostam de fazer parte dela. Comungam dos mesmos interesses da empresa, o que os motiva a trabalhar por ela.

b) Programático: pessoas que fazem parte da empresa somente porque os custos de deixála são muito altos. Preferem não se arriscar, embora insatisfeitas, continuam na empresa, mas não investem efetivamente seu capital humano.

c) Baseado na lealdade: pessoas que se sentem amarradas à organização por um senso de obrigação; esses trabalhadores desejam fazer aquilo que crêem ser o certo para a organização. Mesmo que de forma mais modesta da que ocorre no comprometimento atitudinal, produz dedicação e absorção dos objetivos organizacionais por parte do trabalhador.

Na concepção de Bastos (1993) existem cinco abordagens que podem distinguir a maioria das pesquisas na área de estudo do comprometimento organizacional, são elas: 
a) Afetivo, também chamado atidudinal: o individuo se identifica com a organização e com os objetivos dela e deseja manter-se como membro, de modo a facilitar a consecução desses objetivos. O comprometimento afetivo é aquele associado à idéia de lealdade, desejo de contribuir, sentimento de orgulho em permanecer na organização.

b) Calculativo ou instrumental: comprometimento como função das recompensas e dos custos pessoais, vinculados à condição de ser ou não membro da organização. $O$ comprometimento seria fruto de um mecanismo psicossocial de trocas e de expectativas entre o indivíduo e a organização, em aspectos como salário, status e liberdade.

c) Sociológico: relação de autoridade e de subordinação. O comprometimento do trabalhador se expressa no interesse em permanecer no atual emprego porque percebe a legitimidade da relação autoridade/subordinação. Desta forma, os indivíduos levam para o trabalho tanto uma orientação para seus papéis de subordinados, quanto um conjunto de normas que envolvem os modos corretos de dominação.

d) Normativo: internalização de pressões normativas de comportamento.

e) Comportamental: manutenção de determinadas condutas e de coerência entre seu comportamento e as suas atitudes. O comprometimento "pode ser equiparado com sentimentos de auto-responsabilidade por um determinado ato, especialmente se eles são percebidos como livremente escolhidos, públicos e irrevogáveis". Desta forma, as pessoas tornam-se comprometidas a partir de suas próprias ações, formando um círculo de autoreforçamento no qual cada comportamento gera novas atitudes que levam a comportamentos futuros, em uma tentativa de manter a consistência.

Dentre os diversos modelos de conceituação do comprometimento, o modelo de maior aceitação entre os pesquisadores é o modelo de três dimensões, estabelecido por Meyer e Allen (1993). Eles apresentam um modelo baseado nas proposições que comprometimento é uma força que liga um indivíduo ao curso de ações de relevância para um objetivo e pode ser acompanhado por diferentes opiniões que têm a função de dimensionar o comportamento. O modelo de Meyer e Allen é internacionalmente aceito, tendo sido validado em várias culturas. Os autores conceituam o comprometimento organizacional em três dimensões:

a) Affective Commitment, ou Comprometimento Afetivo: comprometimento como um envolvimento, onde ocorre identificação com os objetivos e valores da organização. Representa algo além da simples lealdade passiva, envolvendo uma relação ativa, na qual o indivíduo deseja dar algo de si para contribuir com o bem-estar da organização. Segundo Meyer e Allen, "Empregados com um forte comprometimento afetivo permanecem na organização porque eles querem (...)";

b) Continuance Commitment e que a literatura trata como Instrumental: comprometimento percebido como altos custos associados a deixar a organização. Segundo Meyer e Allen, "Empregados com (...) comprometimento instrumental permanecem porque eles precisam (...)";

c) Normative Commitment, ou Comprometimento Normativo: comprometimento como uma obrigação em permanecer na organização. Segundo Meyer e Allen, "Empregados com (...) comprometimento normativo permanecem porque eles sentem que são obrigados".

\section{Desenvolvimento do estudo}

Para a mensuração do comprometimento organizacional, a coleta de dados foi realizada através de um questionário composto por duas partes. A primeira parte, formada pelos dados pessoais. A segunda parte é composta por 47 indicadores que foram sorteadas as ordens das afirmativas para evitar o efeito halo. Destes 47 indicadores foram utilizados os seguintes instrumentos: 
a) “Organizational Commitment Questionaire" - OCQ, de autoria de Mowday et al. (1982), que foi adaptado para o contexto brasileiro por Borges-Andrade, Afanasieff \& Silva em 1989, e validado por Bastos em 1992 composto por 9 indicadores que buscam medir o comprometimento organizacional e profissional;

b) $O$ instrumento de Meyer et al.(1993), previamente validado para a realidade brasileira por Medeiros(1997) e por Rocha e Bastos(2000). O instrumento é composto de 18 indicadores, sendo 6 de cada dimensão conceituada pelos autores: afetiva, normativa e instrumental;

c) A escala de Fink composta por 10 indicadores que buscam medir o comprometimento com a equipe;

Apesar do objetivo do estudo delimitar-se ao comprometimento organizacional, utilizamos a escala de Fink, que procura medir o comprometimento com a equipe, pretendendo verificar até que ponto a relação do colaborador com o grupo com o qual interage, tem influência no comprometimento com a organização.

A população pesquisada foi de 189 coloboradores, onde 146 responderam ao questionário através de aplicação direta e 43 aplicação indireta. Há um predomínio de mulheres (62\%), de indivíduos até 35 anos de idade (79\%) e pessoas casadas (45\%). Quanto ao nível de escolaridade, $62 \%$ possuem $2^{\circ}$ grau completo e $58 \%$ dos funcionários têm dependentes.

Em relação ao tempo de permanência na empresa, a média é de 3 anos, onde $35 \%$ dos colaboradores trabalham a menos de 1 ano, 18\% trabalham de 1 a 2 anos, $21 \%$ fazem parte do quadro de funcionários de 2 a 5 anos e um número bastante significativo, $26 \%$ dos colaboradores trabalham na organização a mais de 5 anos.

\section{Resultados}

Em um primeiro momento, analisamos o comprometimento organizacional, através da abordagem de Mowday (1982). A figura 1 indica que 70\% dos colaboradores apresentam alto grau de comprometimento organizacional, $16 \%$ apresentam comprometimento moderadamente positivo e apenas $14 \%$ são descomprometidos.

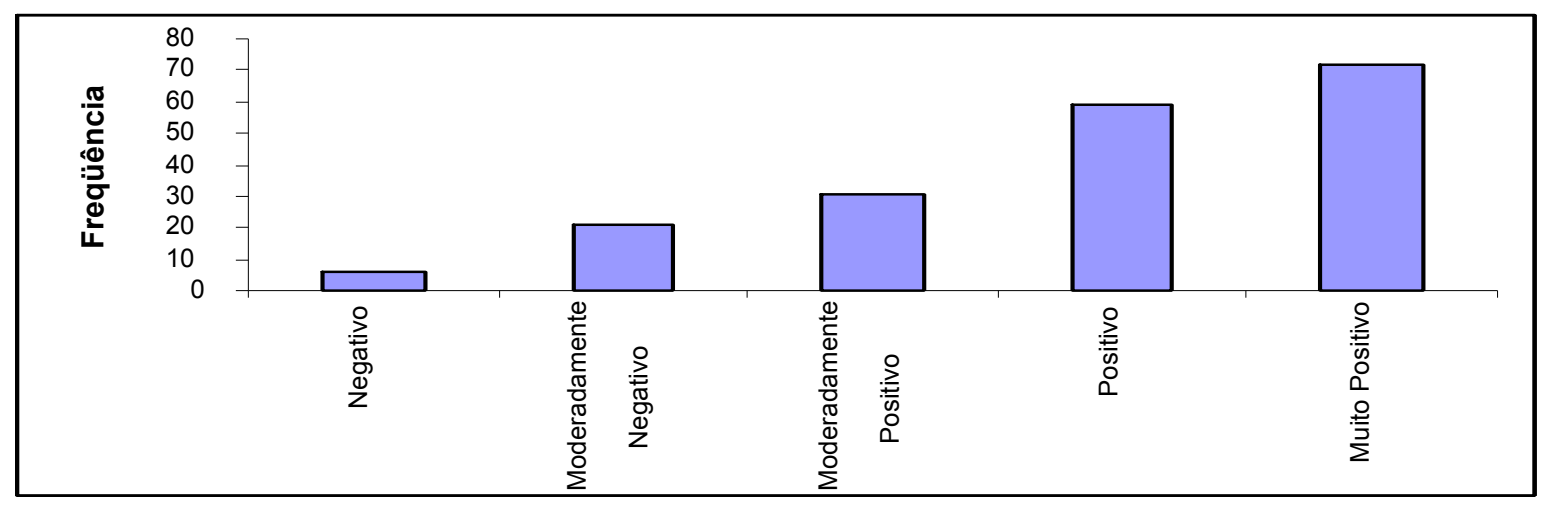

Figura 1 - Nível do comprometimento organizacional

A média de comprometimento organizacional dos colaboradores da empresa apresenta um índice positivo $(5,42)$. Na tabela 1 , são apresentadas as médias de comprometimento organizacional separadas por variáveis.

Coerente com a literatura pesquisada, o grau do comprometimento cresce a medida que aumenta a idade dos indivíduos. Os colaboradores casados apresentam grau de comprometimento superior aos solteiros. Os funcionários que trabalham na empresa a mais de dois anos são mais comprometidos, o que nos permite afirmar que a permanência na organização,é uma conseqüência do comprometimento organizacional. 
Tabela 1 - Médias do comprometimento organizacional por variáveis

\begin{tabular}{|c|c|c|c|c|c|}
\hline Variáveis Pessoais & $\mathbf{N}$ & Média & Variáveis Pessoais & $\mathbf{N}$ & Média \\
\hline Sexo & & & 41 a 45 & 15 & 5,76 \\
\hline Feminino & 116 & 5,46 & 46 a 50 & 9 & 5,86 \\
\hline Masculino & 70 & 5,33 & Acima de 50 & 6 & 5,51 \\
\hline Estado Civil & & & Nível de Renda & & \\
\hline Solteiro & 73 & 5,15 & Até $\mathrm{R} \$ 400,00$ & 75 & 5,11 \\
\hline Casado & 85 & 5,52 & $\mathrm{R} \$ 401,00$ a $\mathrm{R} \$ 550,00$ & 69 & 5,57 \\
\hline Outro & 14 & 5,71 & $\mathrm{R} \$ 551,00$ a $\mathrm{R} \$ 700,00$ & 22 & 5,61 \\
\hline Viúvo & 2 & 6,44 & $\mathrm{R} \$ 701,00$ a $\mathrm{R} \$ 950,00$ & 12 & 5,85 \\
\hline Separado & 9 & 5,80 & $\mathrm{R} \$ 951,00 \mathrm{R} \$ 1200,00$ & 3 & 6,16 \\
\hline Escolaridade & & & Acima de $\mathrm{R} \$ 1200,00$ & 3 & 5,33 \\
\hline $1^{\circ}$ grau incompleto & 25 & 5,79 & $\mathrm{~N}^{\mathbf{0}}$ Dependentes & & \\
\hline $1^{\circ}$ grau & 19 & 5,81 & Nenhum & 79 & 5,22 \\
\hline $2^{\circ}$ grau incompleto & 18 & 5,71 & 1 & 47 & 5,30 \\
\hline $2^{\circ}$ grau & 116 & 5,22 & 2 & 41 & 5,78 \\
\hline Superior incompleto & 4 & 5,61 & 3 & 15 & 5,61 \\
\hline Superior & 5 & 5,82 & Acima de 3 & 7 & 5,61 \\
\hline Idade & & & Tempo de serviço & & \\
\hline Até 25 anos & 87 & 5,16 & Até 1 ano & 67 & 5,23 \\
\hline 26 a 30 & 36 & 5,44 & De 1 a 2 anos & 33 & 4,98 \\
\hline 31 a 35 & 26 & 5,61 & Acima de 2 até 5 anos & 40 & 5,59 \\
\hline 36 a 40 & 10 & 6,17 & Acima de 5 anos & 49 & 5,83 \\
\hline
\end{tabular}

Para identificar os padrões de comprometimento organizacional existentes na empresa utilizou-se o instrumento de Meyer \& Allen (1993), um primeiro resultado consiste nos escores médios das três dimensões como mostra a Figura 2, a seguir:

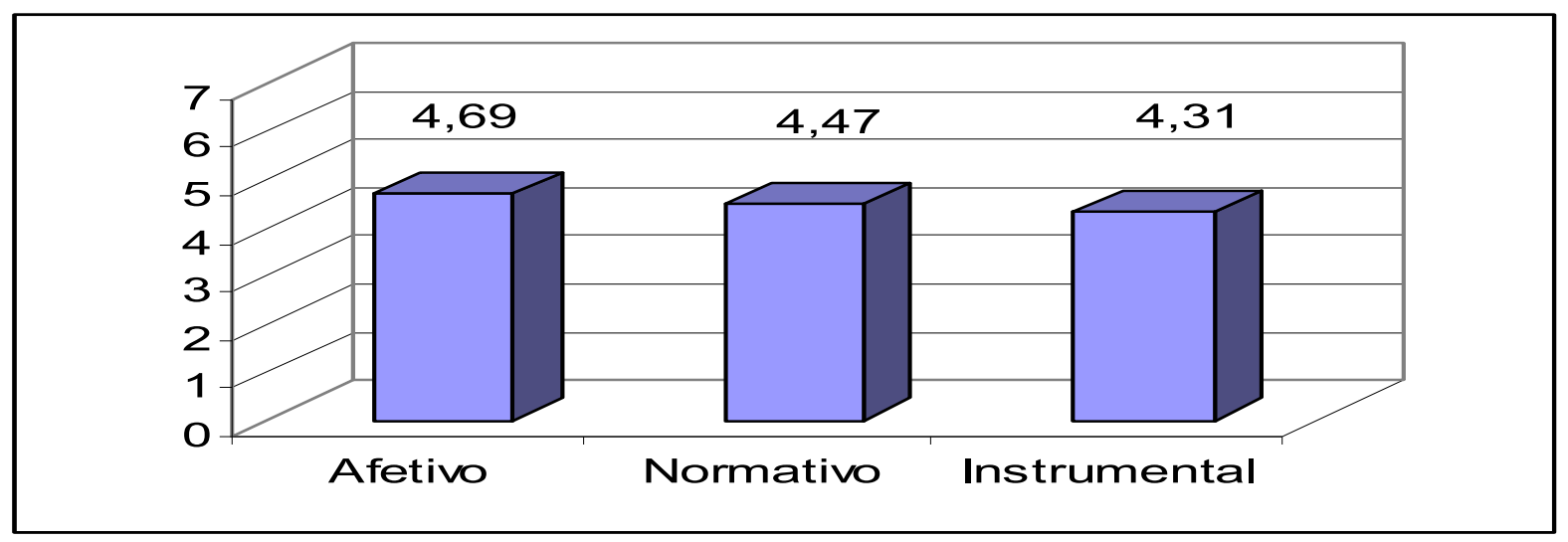

Figura 2 - Escores médios das dimensões do comprometimento

Podemos observar que a dimensão do comprometimento mais forte presente na população estudada é a de base Afetiva, seguida do comprometimento Normativo, e em menor escala o Instrumental. As extremidades inferior e superior da base Afetiva foram 1,83 e 7, da base Normativa de 1,5 e 7, e a base Instrumental com médias que variam de 1,17 a 6,83.

Em relação às afirmativas da dimensão afetiva, podemos observar na tabela 2 que $46 \%$ dos colaboradores apresentam uma união emocional que vai além da lealdade passiva, envolvendo também uma relação ativa na qual desejam dar algo de si para contribuir com uma ação relevante para os objetivos da empresa e $22 \%$ apresentam grau de comprometimento moderadamente positivo. Um número significativo dos colaboradores (32\%) não apresentam comprometimento de base afetiva. 
Tabela 2 - Grau de comprometimento afetivo

\begin{tabular}{|l|l|l|l|}
\hline Média & Freqüência & Percentagem & Grau de comprometimento \\
\hline 1,0 a 2,9 & 19 & $10,05 \%$ & Negativo \\
\hline 3,0 a 4,0 & 42 & $22,22 \%$ & Moderadamente Negativo \\
\hline 4,1 a 4,9 & 41 & $21,69 \%$ & Moderadamente Positivo \\
\hline 5,0 a 5,9 & 52 & $27,52 \%$ & Positivo \\
\hline 6,0 a 7,0 & 35 & $18,52 \%$ & Muito Positivo \\
\hline
\end{tabular}

No que se refere as afirmações da dimensão instrumental, caracterizada pela percepção que seria caro interromper o curso da ação, onde colaboradores estruturam o comprometimento em função das recompensas e permanecem na organização porque precisam, observa-se na tabela 3 que $28 \%$ dos colaboradores apresentam alto grau de comprometimento instrumental, $33 \%$ expressam grau moderadamente positivo e mais de um terço dos colaboradores (39\%) grau negativo.

Tabela 3 - Grau de comprometimento instrumental

\begin{tabular}{|l|l|l|l|}
\hline Média & Freqüência & Percentagem & Grau de comprometimento \\
\hline 1,0 a 2,9 & 20 & $10,58 \%$ & Negativo \\
\hline 3,0 a 4,0 & 54 & $28,57 \%$ & Moderadamente Negativo \\
\hline 4,1 a 4,9 & 62 & $32,81 \%$ & Moderadamente Positivo \\
\hline 5,0 a 5,9 & 42 & $22,22 \%$ & Positivo \\
\hline 6,0 a 7,0 & 11 & $5,82 \%$ & Muito Positivo \\
\hline
\end{tabular}

$\mathrm{Na}$ tabela 4 verifica-se o grau de comprometimento normativo dos colaboradores, colaboradores que estruturam o comprometimento na dimensão normativa, o fazem por acreditar ser o "certo", permanecem na organização porque sentem obrigação de ficar. É interessante observar que a internalização das normas como razão de permanência, o sentimento de obrigação, praticamente inexiste para $41 \%$ dos colaboradores, $23 \%$ expressam grau moderadamente positivo e $36 \%$ apresentam alto grau de comprometimento normativo.

Tabela 4 - Grau de comprometimento normativo

\begin{tabular}{|l|l|l|l|}
\hline Média & Freqüência & Percentagem & Grau de comprometimento \\
\hline 1,0 a 2,9 & 14 & $7,41 \%$ & Negativo \\
\hline 3,0 a 4,0 & 64 & $33,86 \%$ & Moderadamente Negativo \\
\hline 4,1 a 4,9 & 44 & $23,28 \%$ & Moderadamente Positivo \\
\hline 5,0 a 5,9 & 44 & $23,28 \%$ & Positivo \\
\hline 6,0 a 7,0 & 23 & $12,17 \%$ & Muito Positivo \\
\hline
\end{tabular}

A partir da combinação do grau das três dimensões do comprometimento organizacional criou-se oito padrões de comprometimento organizacional. A incidência percentual dos Padrões de Comprometimento entre os indivíduos pesquisados pode ser vista na Figura 3:

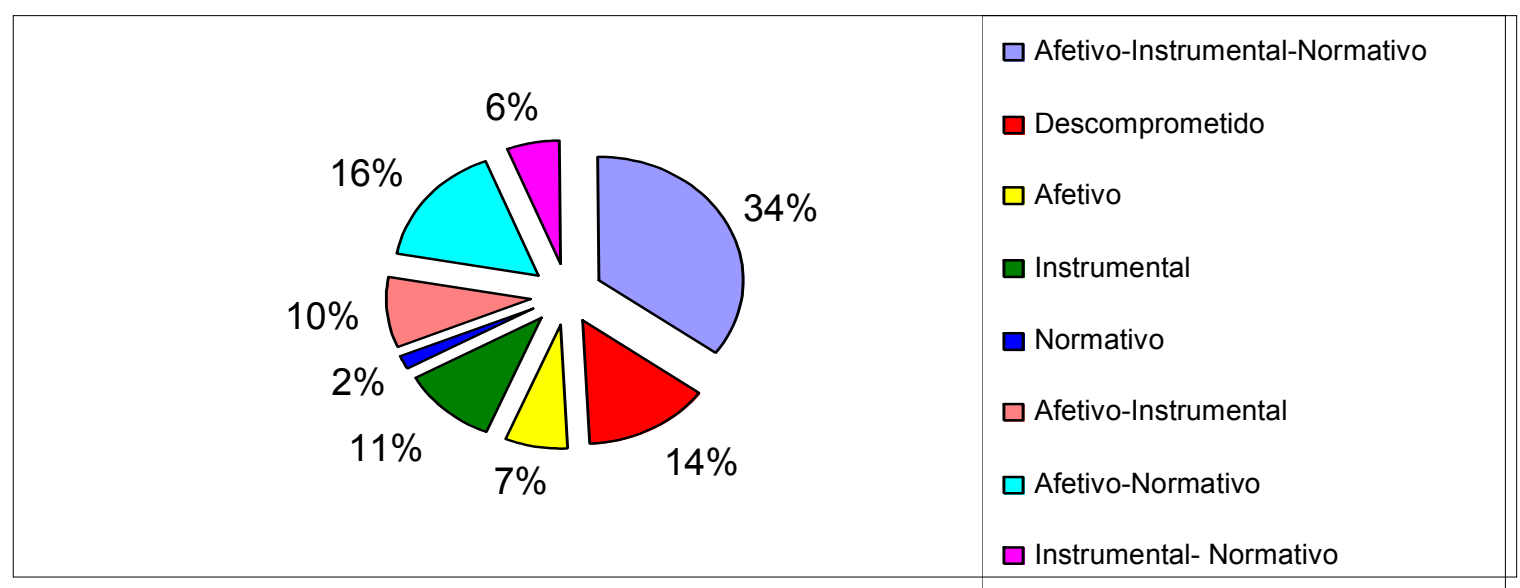

Figura 3 - Distribuição percentual dos colaboradores pelos diversos padrões de comprometimento 
Inicialmente, é interessante verificar que foi possível encontrar colaboradores que combinam as três dimensões de todas as formas possíveis. Ou seja, estruturam o seu comprometimento organizacional combinando, em diferentes graus, as dimensões ou bases propostas por Meyer e Allen (1993).

É possível verificar também que $67,72 \%$ dos colaboradores estabelecem vínculo de comprometimento de base afetiva simples ou combinada com outras bases (instrumental ou normativa). Quando não existe o comprometimento de base afetiva, 10,58\% apresentam comprometimento de base Instrumental simples (permanecem porque precisam), apenas 3 colaboradores $(1,59 \%)$ apresentam comprometimento de base Normativa simples (permanecem porque sentem obrigação de ficar), 5,82\% estruturam o vínculo de comprometimento de base combinada Instrumental-Normativo, e 14,29\% dos funcionários são descomprometidos.

No que se refere às afirmações que são indicativos de comprometimento com a equipe, 53 colaboradores apresentam alto grau de comprometimento com foco na equipe, 126 apresentam comprometimento médio e apenas 10 colaboradores são descomprometidos com a equipe. Destes apenas 1 apresenta comprometimento médio de base afetiva e normativa, entretanto 9 apresentam comprometimento de base instrumental. Nem todos os comprometidos com a equipe o são com a organização, entretanto o colaborador não for comprometido com a equipe tampouco o será com a organização, podendo apenas apresentar comprometimento de base instrumental, ou seja, permanecem porque precisam.

\section{Considerações finais}

Na busca por um esclarecimento sobre o comprometimento organizacional na empresa, foi realizada uma breve pesquisa bibliográfica onde foi possível constatar que níveis elevados de comprometimento organizacional, principalmente de base afetiva, produzem efeitos consideráveis no alcance dos objetivos organizacionais.

Analisando as três dimensões do comprometimento organizacional, pode-se concluir que os comprometimentos afetivos, instrumentais e normativos não são antagônicos e podem existir harmoniosamente, em diferentes graus e combinações.

A dimensão mais fortemente presente nos colaboradores da empresa é a dimensão afetiva, ou seja, indivíduos se identificam e se envolvem com a organização, seguida da dimensão instrumental, permanecem porque precisam e da dimensão normativa, sentem obrigação de ficar.

A partir da combinação das três dimensões do comprometimento organizacional, criou-se oito padrões de comprometimento organizacional, onde a maior concentração de colaboradores encontra-se no padrão $\mathrm{C}$ - comprometido nas três dimensões.

É importante verificar que cerca de $70 \%$ dos colaboradores estabelecem vínculo de comprometimento de base afetiva simples ou combinada com outras bases, ou seja, apresentam uma união emocional que vai além da lealdade passiva, na qual desejam dar algo de si para contribuir com os objetivos da empresa.

Finalizando, cabe ressaltar que esta pesquisa não teve a pretensão de esgotar as possibilidades de análise ou tirar conclusões ambiciosas de um tema tão complexo como os fatores que levam o indivíduo a comprometer-se com os objetivos da organização.

Sabe-se agora, um pouco mais sobre o assunto, porém surge uma indagação sobre quais motivos levam os indivíduos a se comprometer desta ou daquela forma. Assim, outras pesquisas deverão suprir algumas limitações desta, objetivando ampliar o nível de conhecimento que este assunto requer, tanto em nível teórico quanto prático.

\section{Abstract}

This work describes a case study, whose main point of investigation was the organizational commitment. It also identifies level, dimensions and patterns of commitment showed by workers and how personnel characteristics, team relationship and time of permanence in the organization influences the commitment with the company. From data analysis it was brought to a conclusion 
that $70 \%$ of the workers present a high commitment level with the organization, consequently workers willing to help the growing of the researched company.

Key words: organizational commitment, dimensions, commitment patterns.

\section{Referências}

BORGES-ANDRADE, J. E. Comprometimento organizacional na administração pública e em seus segmentos meio e fim. In: REUNIÃO ANUAL DE PSICOLOGIA, 23., Ribeirão Preto, Resumos... Ribeirão Preto: USP/FFCLRP, 1993, p.50.

BASTOS, A. V. B. Comprometimento organizacional: um balanço dos resultados e desafios que cercam essa tradição de pesquisa. Revista de Administração de Empresas, v. 33, p. 52-64, maio/jun. 1993.

BASTOS, A. V. B. Comprometimento no trabalho: Os caminhos da pesquisa e os desafios teóricos-metodológicos. In: Trabalho, Organizações e Cultara. São Paulo: Editores Associados, 1997.

BASTOS, A. V. B. Padrões de comprometimento com a profissão e com a organização: o impacto dos fatores pessoais e da natureza do trabalho. RAUSP. Revista de Administração. São Paulo, v. 35, n. 4, p. 48-60, out./dez. de 2000.

BASTOS, A. V. B.; BRANDÃO, M. G. A.; PINHO, A. P. M. Comprometimento organizacional: explorando este conceito entre servidores de instituições universitárias. Encontro Anual da Associação Nacional dos Programas de PósGraduação em Administração. Rio de Janeiro, v. 9, p. 289-310, 1996.

DAVENPORT, T. O. O capital humano: o que é e por que as pessoas investem nele. São Paulo: Nobel, 2001.

MOWDAY, R. T. et al. Employee Organization Linkages: a psychology of commitment, absenteism and turnover. New York: Academic Press, 1982.

MEDEIROS, C.A.F. Comprometimento organizacional, características pessoais e performance no trabalho: um estudo dos padrões de comprometimento organizacional. UFRN. Dissertação de Mestrado. 1997.

MEYER, J. P.; ALLEN, N. J.; SMITH, C. A.. Commitment to organizations and occupations: extension and test of a three-component conceptualization. Journal of Applied Psychology, n. 78, p. 538-551, 1993.

cross ref

MORAES, R. T. et. al. Comprometimento organizacional, qualidade de vida e stress no trabalho: uma abordagem de diagnóstico comparativo. Revista Brasileira de Administração Contemporânea. São Paulo, v. 1, n. 9, set/1995, p. 169-188, 1995.

ROCHA, A. S. C.; BASTOS, A. V. B. Comprometimento do empregado e contextos organizacionais em mudança: o caso do Banco do Brasil. Revista de Ciências Humanas (CFH/UFSC). Florianópolis, v. 5, p. 117-140, 2000.

SENGE, Peter M. A.. A Quinta disciplina. 2. ed. São Paulo: Best Seller, 1998.

TEIXEIRA, M. G. Comprometimento organizacional: uma análise dos fatores individuais numa empresa de prestação de serviços. In: REUNIÃO ANUAL DA ASSOCIAÇÃO DE PROGRMAS DE PÓS-GRADUAÇÃO EM ADMINISTRAÇÃO, 18, 1994, Curitiba, Anais... Florianópolis: ANPAD, 1994. v. 10. p. 268-286.

VERGARA, SYLVIA C. Gestão de pessoas. 2. ed. São Paulo: Atlas, 2000. 